\title{
Falsas Memórias: questões teórico-metodológicas
}

Cíntia Marques Alves

Ederaldo José Lopes

Universidade Federal de Uberlândia, Uberlândia, Brasil

\begin{abstract}
Resumo: Falsas Memórias (FM's) ocorrem quando uma pessoa lembra de eventos que não aconteceram, situações que nunca presenciou, lugares onde nunca esteve, ou então, se lembra de maneira distorcida do que realmente houve. O objetivo deste artigo é apresentar revisão histórica do tema, alguns modelos teóricos e suas contribuições para a compreensão do assunto. É apresentado o DRM (Deese-Roediger-McDemott), um paradigma usado para se estudar as FM's. Com a teoria, ficou clara a complexidade e importância do tema para a Psicologia e a necessidade dos psicólogos estarem atentos ao assunto, principalmente aqueles que trabalham diretamente com a memória das pessoas.
\end{abstract}

Palavras-Chave: Falsas Memórias. Modelos teóricos. Procedimento DRM.

\section{False Memories: theoretical and methodological issues}

\begin{abstract}
False Memories (FM's) occur when a person remembers events that never happened to him, situations at which he/she was not present, places where he/she has never been, or when he/she remembers some event differently from what really happened. The purpose of this work was to present a historical review of FM's, some theoretical models and their contributions to the comprehension about them. The DRM (Deese-Roediger-McDemott), which is used to study FM's, is also presented. We could see the importance and the necessity of this study for Psychology and for psychologists, mainly those who work directly with the people's memory.
\end{abstract}

Keywords: False Memories. Theoretical models. DRM Paradigm.

\section{Falsas Memorias: cuestiones teórico-metodologicas}

Resumen: Falsas Memorias (FM's) ocurren cuando una persona recuerda eventos que no sucedieron, situaciones que nunca presenció, lugares donde nunca estuvo, o entonces, recuerda de manera destorcida los acontecimientos que realmente sucedieron. El objetivo de este artículo es presentar una revisión histórica del tema, algunos modelos teóricos e sus contribuciones para la comprensión del asunto. Presentamos el DRM (Deese-Roediger-McDemott), un paradigma usado para estudiar las falsas memorias. Con la teoría quedó claro la complejidad e importancia del tema para la Psicología y la necesidad de los Psicólogos estar atentos al asunto, principalmente aquellos que trabajan directamente con la memoria de las personas.

Palabras clave: Falsa Memorias. Modelos teóricos. Procedimientos DRM. 


\section{Falsas Memórias: definição e teorias}

A memória é conceituada por Sternberg (2000) como "o meio pelo qual você recorre às suas experiências passadas a fim de usar essas informações no presente; refere-se a um processo de mecanismos dinâmicos associados à retenção e recuperação da informação" (p. 204). Porém, ela pode causar vários problemas. Às vezes, um fato é distorcido; outras, esquecido; mas existem aqueles que, por mais que a pessoa tente, nunca consegue esquecer. $\mathrm{O}$ estudo destes problemas ocorridos por erros da memória é tão importante quanto fascinante. $\mathrm{O}$ fenômeno das Falsas Memórias é um exemplo desta classe de erros.

As Falsas Memórias (FM's) podem ser definidas como lembranças de eventos que não ocorreram, de situações não presenciadas, de lugares jamais vistos, ou então, de lembranças distorcidas de algum evento (Roediger \& McDermott, 2000; Stein \& Pergher, 2001). São memórias que vão além da experiência direta e que incluem interpretações ou inferências ou, até mesmo, contradizem a própria experiência (Reyna \& Lloyd, 1997). As FM's podem ser elaboradas pela junção de lembranças verdadeiras e de sugestões vindas de outras pessoas, sendo que durante este processo, a pessoa fica suscetível a esquecer a fonte da informação ou elas se originariam quando se é interrogado de maneira evocativa (Loftus, 2005).

É preciso diferenciar este tipo de memória de uma mentira deliberada. Nas FM's a pessoa sinceramente acredita que viveu aquele fato, e na mentira ela está consciente de que o narrado por ela não aconteceu, mas sustenta a história por algum motivo particular (Payne, Elie, Blackwell \& Neuschatz, 1996).

Neste último século, pesquisas sobre a falsificação da memória se intensificaram. E o interesse provém de que o fenômeno pode ser visto tanto em contextos laboratoriais, quanto nos do cotidiano das pessoas, em situações de psicoterapias e na área jurídica (Loftus, 1997; Roediger \& McDermott, 2000).

Os primeiros estudos experimentais sobre o assunto, tiveram início com as pesquisas de Binet em 1890, na França e Stern em 1910, na Alemanha (Roediger \& McDermott, 2000). Tanto Binet quanto Stern pesquisaram a falsificação e ilusão da memória nas crianças e examinaram como a recordação delas poderia ser alterada a partir de sugestões de adultos. Em situação de recuperação livre, as crianças cometiam poucos erros, entretanto, quando as questões envolviam comentários sugestivos elas apresentavam muitos erros.

Bartlett (1932) foi o pioneiro nos estudos da falsificação de memórias nos adultos. Para ele, o ato de recordar algum fato é um processo construtivo, baseado nas experiências, expectativas e conhecimentos prévios do indivíduo, bem como nos esquemas que ele possui (Stein \& Neufeld, 2001; Stein \& Pergher, 2001). A idéia do autor era a de que os detalhes de uma experiência específica não podem ser totalmente relembrados, mas seus temas gerais ficam gravados na memória por mais tempo. Assim, quando as pessoas tentam recordar fatos bem antigos, elas são guiadas por temas e esquemas gerais do evento e completam as lacunas já esquecidas com detalhes consistentes a estes esquemas (Roediger \& McDermott, 2000).

Outro trabalho que merece destaque é o de Loftus e Palmer (1974), que estudaram a recordação de testemunhas oculares. Eles acrescentaram à avalição das FM's em adultos um paradigma que atualmente é conhecido como Efeito da Falsa Informação (Misinformation Effects), no qual, logo após o evento, é apresentada uma informação falsa mas coerente com ele e, em seguida, testa-se a memória. Os resultados mostraram que os sujeitos apresentam um aumento nos índices de reconhecimento falso e uma diminuição nos do verdadeiro (Loftus, 1997; Loftus \& Hoffman, 1989; Stein \& Neufeld, 2001; Stein \& Pergher, 2001).

As FM's podem se originar de duas maneiras distintas: de forma espontânea e implantada ou sugerida. As FM's espontâneas são as criadas internamente no indivíduo como resultado do processo normal de compreensão do evento (Reyna \& Lloyd, 1997; Stein \& Pergher, 2001). Este tipo de distorção simples acomete a todos no dia-a-dia, com questões aparentemente sem importância. As FM's sugeridas ou implantadas dizem respeito àquelas que resultam de uma sugestão externa ao indivíduo, seja esta proposital ou não, cujo conteúdo não faz parte do evento experienciado, mas contém características coerentes com o fato. (Reyna \& Lloyd, 1997). 
De modo geral, os relatos são frutos da compreensão do evento e nem sempre isso acarreta algum dano a alguém. Porém, a distinção destas memórias faz-se importante em situações em que é exigido da pessoa que relate exatamente o que aconteceu e não aquilo que compreendeu ou inferiu do fato. O fenômeno das FM's vem sendo explicado por três modelos teóricos, que com suas descobertas e limitações teóricas e práticas têm embasado este tema tão amplo, a saber:

\section{A) Construtivismo}

Loftus (1997, 2003b) alega que a memória é algo precioso na vida do indivíduo, pois dá a cada um sua identidade, ligando-o aos seus familiares e amigos. A princípio, a memória pode parecer fixa e estabelecida, mas ela é maleável e inacurada, podendo ser criada, modificada e até mesmo perdida ao longo da vida. A partir dos diversos estudos de Loftus e Hoffman (1989) eles concluíram que a memória das pessoas não é somente a lembrança daquilo que elas fizeram, mas é combinação, também, de tudo o que pensam, acreditam e recebem do meio externo.

Para os construtivistas, as pessoas se lembram do que elas entendem ser o significado do fato e não, necessariamente, dele em si, e isto pode gerar a lembrança de informações incorretas e até mesmo, de falsas memórias. Os eventos são interpretados conforme sua vivência e as interpretações integradas às estruturas semânticas do indivíduo, conhecidas como esquemas. Portanto, o conteúdo da informação é facilmente modificado na memória (Brainerd \& Reyna, 2005).

De acordo com Loftus $(1997,2003 a)$ as FM's são criadas através de sugestões ou de imaginações. No primeiro caso, as reais combinam-se com o conteúdo sugerido por terceiros, o que pode gerar uma falsa memória tão real que as pessoas fornecem detalhes e até mesmo expressam suas emoções sobre o evento que na verdade não aconteceu. Um simples procedimento de sugestão é suficiente para fazer com que algumas construam suas lembranças de forma complexa, viva e detalhada (Loftus, 2005). No segundo caso, na imaginação, a pessoa é levada a deixar a mente livre e imaginar, sem a preocupação de o fato ter sido real ou não, experiências e eventos específicos, mas que talvez nunca tenham ocorrido. A imaginação leva-as a acreditarem que praticaram tan- to coisas pequenas e sem importância, como também eventos complexos, tais como os vários casos das que alegaram em psicoterapias, com técnicas de hipnose e/ou de imaginação livre, que haviam sido estupradas na infância (Loftus, 1995, 1997, 2003b). Pesquisas comprovam que pessoas podem desenvolver uma crença e memória de um evento autobiográfico que não aconteceu, simplesmente imaginando sua ocorrência, produzindo assim FM's (Mazzoni, 2005; Mazzoni \& Memon, 2003).

O fato de que ocorre uma falha na memória é indiscutível. O problema, neste modelo teórico, é saber se ela acontece durante o processo de armazenamento ou na recuperação (Loftus, 1995). Os Construtivistas tentaram explicar isto em termos da natureza construtiva da memória, que, para eles, ela é maleável e construída ao longo da vida. Portanto, os erros existentes ocorrem porque outras experiências do indivíduo ou até mesmo seu raciocínio sobre o vivenciado podem transformar, distorcer ou contaminar a memória. Os eventos são integrados às inferências que vão além do fato, o que seria uma hipótese de falha no armazenamento da memória (Loftus, 1995), que nesta teoria é influenciada e modificada pelo raciocínio, já que os efeitos da falsa informação mostram a existência de transformações nela influenciadas por informações após o evento (Loftus, 1995).

Autores da Teoria do Traço Difuso têm replicado estes achados sobre a memória construtiva e a grande dúvida para eles é se estas falhas nela são realmente causadas porque os eventos se incorporam às interferências, para além da experiência. Se isto for verdade, os julgamentos da memória para inferências e eventos experienciados teriam que ser relacionados (Reyna \& Brainerd, 1995). Algumas vezes, quando esta relação de dependência foi testada ela se mostrou falsa. O julgamento de memória para sentenças que geram inferências é completamente não relacionado com ao das originais. Por exemplo, julgar as sentenças: "O pássaro está na gaiola" e "A gaiola está debaixo da mesa" não está relacionado ao da inferência: "O pássaro está embaixo da mesa". Defende-se então que a representação de eventos experienciados e a representação das inferências são acessadas independentemente. Estes achados sugerem que a memória para o even- 
to em si é dissociada do entendimento da experiência, contrariando, assim, os pressupostos do Construtivismo (Reyna \& Brainerd, 1995).

Estas evidências têm mostrado, portanto que, embora ocorram inferências e elaborações, isso não significa que a memória para o evento tenha sido distorcida ou que haja falha no armazenamento da informação e que, por consequiência, os traços da experiência não mais existam. Não se duvida que as elaborações possam interferir na recordação. $\mathrm{O}$ que não é correto é dizer que elas afetem totalmente a memória original do evento, eliminando-a completamente (Reyna \& Brainerd, 1995).

\section{B) Monitoramento da fonte}

Outro modelo teórico que busca explicar o fenômeno das FM's é o Monitoramento da Fonte proposto por Johnson, Hashtroudi e Lindsay (1993), que buscaram responder a algumas questões que, através da Teoria do Construtivismo, ainda permaneciam obscuras para eles. A construção dos fatos não gerava, por si só, erros de memória, como alegavam os construtivistas; tanto em experimentos laboratoriais quanto em condições da vida diária era claro que as pessoas algumas vezes tinham sucesso na discriminação da origem da experiência mental, mas em outras fracassavam. Isto foi atribuído à hipótese de que existiriam mecanismos que permitiriam discriminar corretamente a origem de algumas experiências, mas não de todas, sendo processos de julgamento pelos quais as experiências são atribuídas às diferentes fontes (Mitchell \& Johnson, 2000).

Além disso, eles não acreditavam na idéia dos construtivistas de que a memória para a experiência é necessariamente integrada às inferências e outras fontes de informação. Para eles, tanto a do evento original quanto a da informação posterior permaneciam separadas e intactas. Porém as sobre as respectivas fontes é que poderiam não ser acessadas. Assim, as FM's ocorrem porque estas são confundidas ou mal-atribuídas (Jonson \& cols., 1993).

Para Johnson e cols (1993) a tarefa primeira para alguém relembrar um evento é o monitoramento da fonte, ou seja, de onde veio determinada informação. Este é, portanto, um conjunto de processos cognitivos envolvidos na atribuição sobre a origem das experiências mentais, ou seja, discriminar se uma informação provém de sonhos, experiências reais ou imaginadas (Johnson \& cols., 1993; Johnson \& Mitchell, 2002; Mitchell, Johnson \& Mather, 2003).

De acordo com Johnson e cols. (1993), há três tipos de monitoramento da fonte:

a) O Interno-Externo da Realidade (realitymonitoring) (Brainerd \& Reyna, 2005; Johnson \& Raye, 1981, citados por Johnson \& cols., 1993): capacidade para discriminar entre memórias de eventos reais externos e as dos que de fato não foram vividos, mas somente imaginados. As memórias são verdadeiras na medida em que se referem aos eventos que estão dentro de um leque de experiências possíveis, mas falsas quando se originam de eventos internos mal identificados. Este monitoramento da fonte é melhor e mais eficiente.

b) O Externo da Fonte: discriminar entre dois fatores externos (auditivo, visual, voz masculina ou feminina), aquele de onde saiu a informação. Ele possui características mais associadas a detalhes de percepção.

c) O Interno da Fonte: discriminar entre fontes geradas internamente no indivíduo (pensar, imaginar, raciocinar, sonhar). Ele possui características mais associadas a operações cognitivas.

O monitoramento da fonte pode ser feito de maneira rápida e automática sem consciência da ação, baseada em julgamentos heurísticos sobre as características das memórias ativadas; ou de modo mais lento e controlado, através de processos cognitivos complexos e sistemáticos (Johnson \& cols., 1993; Johnson \& Mitchell, 2002; Mitchell \& Johnson, 2000). Os critérios utilizados no julgamento do monitoramento da fonte tendem a ser mais rígidos e severos do que os de decisão usados para fazer um julgamento de reconhecimento. Ele pode reduzir vieses da memória e este sucesso, depende, portanto, das combinações de fontes que são utilizadas (Hicks \& Marsh, 1999; Johnson \& cols., 1993); quanto mais semelhantes elas forem, mais difícil será o monitoramento correto entre elas, gerando, assim, maior chance de aparecimento das FM's (Payne \& cols., 1996).

A atribuição errada da fonte acontece quando a pessoa tenta lembrar fatos que nunca ocorreram, pondo imagens vívidas que lhes saltam à mente, às lembranças de situações passadas que, na realidade, não existiram. Em outras ocasiões, lembram facilmen- 
te do evento ocorrido, mas não do momento e da hora corretos. Às vezes, atribuem uma imagem à imaginação quando na verdade, este fato veio de algo lido ou ouvido. Acreditam ter feito alguma coisa e, quando percebem, tudo não passou de uma imaginação ou sonho. Os erros podem ser tão banais quanto estes exemplos, até os considerados bastante problemáticos, em que a pessoa alega com precisão que foi abusada sexualmente na infância, quando tudo não passou de um sonho (Johnson \& Mitchell, 2002; Mitchell \& Johnson, 2000).

Alguns fatores como o tipo, a quantidade e qualidade da informação ativada, vieses da recordação, objetivos da atividade, semelhança das fontes, tempo entre o evento e a recordação, o disponibilizado para a recordação, atenção dividida durante o teste, conhecimentos anteriores, operações cognitivas, emoções e informações contextuais podem interferir na correta atribuição da fonte (Johnson \& cols., 1993; Johnson \& Mitchell, 2002; Mitchell \& Johnson, 2000; Reyna \& Lloyd, 1997).

A teoria do Monitoramento da Fonte alega que quando ele é explícito, este fato pode diminuir o índice das FM's (Lindsay \& Johnson, 1989, citados por Reyna \& Lloyd 1997) e quando não é explicitamente exigido, o índice das FM's pode aumentar, diminuir ou manter-se inalterado (Reyna \& Lloyd, 1997). Outro fato importante é que como 'o monitoramento da fonte é resultado de um processo relativamente complexo de atribuição, essa habilidade aumenta com o desenvolvimento da idade' (Johnson \& cols., 1993, p. 07), mas esta questão também tem sido controversa.

\section{C) Teoria do traço difuso (FTT)}

A Teoria do Traço Difuso (Fuzzy Trace Theory-FTT) foi inicialmente desenvolvida por Brainerd e Reyna no início da década de 1990 para explicar e contradizer os resultados de que a memória é intimamente relacionada com o raciocínio, como havia sido predito por modelos teóricos anteriores, tais como no do Processamento de Informação e no Construtivista e que portanto, para se ter um raciocínio preciso era necessário ter uma memória precisa ou vice-versa (Reyna \& Brainerd, 1995). Além desta controvérsia, a FTT aponta que a memória para a fonte da informação é um detalhe literal que pode, ao longo do tempo, se fragmentar e por fim, se tornar inacessível quando comparada à de essência do evento (Reyna \& Lloyd, 1997).

Em algumas condições experimentais, a FTT alega que as FM's podem ser mais duradouras e resistentes do que as verdadeiras, sendo relatadas com detalhes mais vivos de sua apresentação em testes de recordação ou reconhecimentos, principalmente nos casos em que os distratores não apresentados são semanticamente relacionados às palavras alvos (Ceci \& Bruck, 1998; Payne \& cols., 1996; Reyna \& Lloyd, 1997).

A FTT possui duas hipóteses para explicar o fenômeno das FM's. A primeira é que a memória não é um sistema unitário, mas possui dois independentes que funcionam sem interconexão, saber: Memória Literal e de Essência, que são codificadas separadamente e recuperadas independentemente (Brainerd \& Reyna, 2005; Brainerd, Stein \& Reyna, 1998; Reyna \& Brainerd, 1998; Reyna \& Lloyd, 1997). A Literal é aquela em que o indivíduo consegue se recordar dos detalhes específicos do evento, ou seja, é possível se lembrar literalmente do fato vivido; por exemplo, quando a pessoa lembra exatamente a roupa que usava no seu aniversário de cinco anos atrás ou quando sabe que guardou uma tesoura de cabo vermelho no armário da cozinha, na segunda gaveta à direita da pia. As de Essência são as que a pessoa não consegue se lembrar de detalhes precisos, mas têm uma idéia do evento como um todo, ou seja, ela guarda na memória, o significado geral daquilo que viveu; por exemplo, lembrar do aniversário de cinco anos atrás, sem se recordar da roupa que usava e saber que guardou um objeto em algum armário da casa, mas não saber o que nem onde guardou. Elas se diferenciam basicamente no conteúdo e na precisão de detalhes (Reyna \& Brainerd, 1998; Stein \& Neufeld, 2001).

A segunda hipótese diz respeito à durabilidade das memórias. As de Essência são mais amplas, robustas e duradouras e armazenam apenas as informações inespecíficas do evento. As Literais codificam a informação de maneira precisa e detalhista, porém são mais suscetíveis ao esquecimento e à interferência, tornando-se inacessíveis mais rapidamente que a de Essência (Brainerd \& Reyna, 2005; Reyna \& Lloyd 1997). As FM’s ocorrem, portanto, ou quan- 
do as memórias de Essência são recuperadas no momento em que se deseja a recuperação das literais, ou quando há recuperação errada destas (Brainerd \& Reyna, 2005; Ceci \& Bruck, 1998).

A FTT é embasada em alguns princípios que regem os seus achados. Estes giram em torno da distinção entre a memória Literal e de Essência (Brainerd \& Reyna, 1998a, 2002, 2005). O primeiro princípio diz respeito ao armazenamento paralelo dos traços literais e de essência. Como as memórias Literais e de Essência são armazenadas na mesma experiência, seria coerente supor que houvesse uma forte interconexão funcional entre elas, porém estudos têm demonstrado que esta interdependência não existe, e ao contrário, indicam que a codificação se dá com processos de armazenamento paralelos (Brainerd \& Reyna, 1998a). Os indivíduos processam a forma superficial da informação separadamente da do significado que ele atribuiu ao evento, sendo este iniciado cerca de vinte a trinta milissegundos após o começo do da forma literal e bem antes que este se complete (Brainerd \& Reyna, 2002). O processamento e armazenamento do significado se dão simultaneamente ao literal, porém, independentes, por isso, as pessoas podem reter o significado do alvo até mesmo se este for esquecido. Como os alvos têm múltiplos significados, elas armazenariam mais de um traço de essência para um único alvo, em níveis variados de especificidade (Brainerd \& Reyna, 2005). Por exemplo, ao se ler coker spaniel, os conceitos cão de caça, de fazenda e cachorro de estimação podem também ser ativados e armazenados sem terem sido apresentados.

O segundo princípio é sobre a recuperação dissociada dos traços literal e de essência. Para Brainerd e Reyna (1998a, 2002) o processo de recuperação é baseado em alguns fatores. Os literais e de essência são acessíveis, sendo que os itens experienciados (alvos) são pistas mais recuperadoras dos literais em testes de reconhecimento; e itens não experienciados (distratores), mas que preservam o conteúdo, são pistas recuperadoras de traços de essência em testes de reconhecimento. Os acertos são baseados em memórias Literais e os alarmes falsos na de Essência, ambos em testes de recordação e reconhecimento. Além disso, os traços literais são melhor recuperados quando há repetição do mesmo item e os de essência quando diferentes exemplares de um mesmo significado são apresentados sem repetição de nenhum item. Por fim, o esquecimento se dá mais rapidamente para a memória Literal do que para a de Essência, portanto, as FM's podem persistir mais ao longo do tempo (Brainerd \& Reyna, 2005).

O terceiro princípio apontado por Brainerd e Reyna (1998a, 1998b, 2002) refere-se à natureza da recordação explícita dos fatos. Com relação às FM's, a recuperação literal e de essência é concebida como processos opostos, já que a literal tende a diminuir e a de essência a aumentar as FM's. Há um ponto na teoria que alega que os testes de reconhecimento provocam duas experiências subjetivas de memória. A primeira é que a recuperação dos traços literais fornece uma lembrança viva, chamada de recordação ou sentimento de lembrança que produz um acesso para representações de estruturas literais bem definidas. A segunda é que a recuperação dos traços de essência produz um acesso à informação semântica e fornece uma forma mais geral de lembrança, chamada de familiaridade ou sensação de conhecimento, em que os itens não vividos são semelhantes aos itens vividos, mas suas ocorrências não explicitamente recordadas (Kelley \& Jacoby, 2000). Entretanto, em situações em que os traços de essência são extremamente fortes, eles podem gerar altos níveis de recordação vívida da experiência para certos tipos de itens não vividos (Brainerd \& Reyna, 2002, 2005).

O quarto princípio é baseado na distinção entre respostas que dizem respeito ao julgamento de identidade/não identidade sobre as memórias literais e entre respostas que dizem respeito ao julgamento de semelhança nas de essência. No momento em que a memória literal é recuperada ocorre um julgamento categórico de identidade/não identidade das formas literais do inquérito. Quando a de Essência é recuperada, podem haver dois julgamentos: de níveis de semelhança ou categórico de identidade, quando isto é tão forte que causa um sentimento de recordação explícita (Brainerd \& Reyna, 1998a, 1998b). Dentro deste princípio, a recuperação literal fornece uma aceitação de alvos associada com a rejeição de distratores sem se importar se estes formam significados consistentes com aqueles. Além disso, ela pode criar julgamentos de identidade para os alvos e de não identidade para os distratores. A recuperação da essência fornece uma aceitação para os alvos por- 
que o significado da lembrança é bastante robusto, mas também traz alarmes falsos para os distratores relacionados ao alvo já que o conteúdo semântico entre eles é suficientemente forte (Brainerd \& Reyna, 1998a,1998b).

O último princípio diz respeito à variabilidade desenvolvimental das FM's. A aquisição, retenção e recuperação tanto da Literal como da de Essência progridem ao longo do desenvolvimento da pessoa, da infância até a fase adulta, mas não num padrão uniforme. Ambas podem declinar, mas a Literal declina muito mais rapidamente que a de Essência (Brainerd \& Reyna, 2005).

Ao se estudar o fenômeno das FM's, dois tipos de respostas podem ocorrer: as de base mnemônicas, quando os itens do teste produzem recuperação das memórias que foram armazenadas, na apresentação dos alvos e respostas de base não mnemônicas, quando não há recuperação de memórias do alvo e os indivíduos recorrem a uma variedade de respostas enviesadas (Brainerd \& Reyna, 1998a). Para as respostas com base mnemônica, tanto nos estudos de reconhecimento falso quanto nos do efeito da sugestão, pode haver a rejeição incorreta de itens alvos, ou seja, dos que foram apresentados; como também o alarme falso, ou seja, aceitação dos itens não apresentados, mas que possuem conteúdos semelhantes aos dos alvos, conhecidos por distratores críticos. Já na resposta com base não mnemônica, o indivíduo aceita incorretamente os distratores não relacionados aos itens alvos e não apresentados (Stein \& Neufeld, 2001).

Nenhum dos modelos teóricos apresentados aqui carrega em si a explicação total de todas as questões concernentes ao assunto. Porém, a Teoria do Traço Difuso (FTT) tem sido a mais amplamente usada para explicar este fenômeno das FM's

Afim de estudar o fenômeno das Falsas Memórias, os pesquisadores têm utilizado alguns métodos diferenciados de acordo com seus objetivos, tais como: experimentos em que se usam sentenças livres, histórias em prosa, sequiência de slides, vídeos, figuras e listas de palavras associadas. Em cada um destes métodos, é possível se obter evidências de FM's, embora os efeitos da magnitude dependam da estratégia empregada (Roediger \& McDermott, 1995)
Um método muito utilizado pelos pesquisadores é o DRM (procedimento de palavras associadas Deese/ Roediger/ McDermott), já que por ele é possível investigar a criação e a recuperação das FM's com um alto nível de controle experimental (Gallo, Roediger \& Mcdermott, 2001; Ghetti, Qin \& Goodman, 2002; Hicks \& Starns, 2005). Neste procedimento, as pessoas geralmente registram suas FM's com alta confiança na memória e estão prontas a fazer atribuições quanto à fonte ou contexto em que o distrator crítico foi supostamente apresentado (Hicks \& Marsh, 1999; Hicks \& Starns, 2005). Além disso, neste paradigma, as FM's eliciadas são muito persistentes e não facilmente reduzidas (Hicks \& Marsh, 2001).

Este procedimento é adaptado de um experimento realizado por Deese (1959) em que o autor estava interessado em predizer a ocorrência das palavras extra-listas no teste de recordação livre. Para tanto, ele trabalhou com 36 listas de doze palavras semanticamente associadas; cada uma contendo uma palavra que traduzia sua essência temática e que recebeu o nome de distrator crítico. As listas foram construídas a partir das normas de associação de palavras pela obtenção do Forward Associative Strength (FAS) que é a tendência do distrator crítico eliciar os itens da lista, ou seja, a força associativa dele para com cada alvo, de acordo com as normas de um estudo de Russell e Jerkins (apud Deese, 1959). Em algumas listas, o índice de recordação dos distratores críticos foi grande e em outras, quase inexistente. Deese hipotetizou que uma outra variável, o Backward Associative Strength (B.A.S.) - força associativa de cada alvo para com o distrator crítico - ou seja, a tendência média de cada alvo eliciar o distrator crítico - era crucial na produção dos efeitos de recordação falsa em algumas listas. Quando estas tinham um alto B.A.S., elas produziam maiores índices de FM's (Deese, 1959)

No início da década de 1990, Roediger e McDermott (1995) adaptaram o estudo de Deese e realizaram dois estudos, os quais, juntamente com o de Deese, deram origem ao procedimento DRM. No primeiro estudo (E1), eles apenas reaplicaram o de Deese, usando as seis listas de doze palavras que mais facilitaram o aparecimento da recordação incorreta dos distratores críticos. Os participantes re- 
cordaram não só as palavras apresentadas, mas também $40 \%$ dos distratores críticos. No teste de reconhecimento, não houve diferença significativa entre o reconhecimento verdadeiro (86\%) e o falso (84\%). É possível que os resultados do teste de reconhecimento tenham sido afetados pelo teste de recordação. Para testar esta afirmação, no E2, após a apresentação das listas, metade deles fazia um teste de recordação e a outra de um de matemática. Aqui, os indivíduos recordaram falsamente $55 \%$ dos distratores críticos. No reconhecimento, a taxa de reconhecimento falso foi mais alta para os que fizeram teste de recordação (81\%) do que os de matemática $(72 \%)$ e a taxa do reconhecimento correto com recordação (79\%) foi maior do que a sem recordação $(65 \%)$ ou seja, lembrar realmente interfere no reconhecer tanto para o correto quanto o falso (Roediger \& Mcdermott, 1995).

Vários artigos têm sido publicados com este procedimento, cada um deles testando uma variável diferente e obtendo resultados importantes com relação às FM's. Em todos eles, índices de recordação ou reconhecimento falso sempre são encontrados. As mudanças destas variáveis incluem a forma da apresentação das palavras (Gallo, Mcdermott, Percer \& Roediger, 2001; Miller \& Gazzaniga, 1998); momentos diferentes da testagem das listas (McDermott, 1996; Stein \& Pergher, 2001); variação no número dos itens delas e de palavras associadas (Robinson \& Roediger, 1997); mais de uma apresentação delas (McDermott, 1996); de um teste de memória (Payne \& cols., 1996), seja este o de recordação livre (Hicks \& Marsh, 1999) ou o de reconhecimento (Hicks \& Marsh, 2001); uso de diferentes instruções aos participantes (Brainerd \& Reyna. 1998b), bem como o momento delas (Gallo, Roediger \& cols., 2001); informações ou não sobre as FM's (Gallo, Roberts \& Seamon, 1997); presença ou não do distrator crítico (McDermott \& Roediger, 1998); associações de palavras às figuras (Israel \& Schacter, 1997); tentativa de correlacionar as listas (Stadler, Roediger \& McDermott, 1999) e os fatores delas que alteram as FM's (Roediger \& cols., 2001); uso da recordação para reduzir o reconhecimento falso (Gallo, 2004); relacionamento entre as FM's e a de trabalho (Watson, Poole, Bunting \& Conway, 2005), e tantos outros que a literatura oferece.
Algumas teorias têm sido propostas afim de explicar os achados neste procedimento específico. Elas são: a do Traço Difuso (FTT), a de Ativação e Monitoramento (AMT) e Heurística da Distinção.

A FTT, proposta por Brainerd e Reyna (1998a,1998b, 2002), concentra suas explicações na diferenciação dos traços da memória Literal (itens da lista- alvos) e da de Essência (itens não apresentados nas listas, mas semanticamente semelhantes aos delas- distratores críticos). Para a FTT o distrator crítico é codificado, armazenado e depois relembrado porque ele é consistente com a representação de essência. A noção aqui é que uma sobreposição semântica ou uma similaridade de significados das palavras exercem uma influência automática na recuperação, resultando numa experiência subjetiva de familiaridade (Gallo \& Roediger, 2002). O distrator crítico não precisa ser ativado antes da recuperação, mas apesar disso, ele é falsamente relembrado porque é consistente com os alvos. Nesta teoria ocorre o armazenamento dos itens literais e de essência, o que vai causar, depois, o falso reconhecimento.

A Teoria de Ativação e Monitoramento (AMT) foi proposta por Roediger, Watson, McDermott e Gallo (2001) para explicar os achados no DRM quanto ao falso reconhecimento e recordação. Ela atribui funções tanto para a ativação quanto para o monitoramento.

A ativação da memória ocorre quando as listas são apresentadas, mas também pode ser durante os testes. De acordo com esta teoria, propriedades salientes da palavra seriam pensadas como representadas em redes de conexão através das quais, a ativação se expande quando a palavra é apresentada. A quantidade de ativações é determinada por quão próximas estão as palavras, ou seja, por sua conectividade na rede. Isto faz com que os distratores críticos, altamente associados por propriedades léxicas ou semânticas, sejam ativados e falsamente relembrados (Brainerd \& Reyna, 2005; Gallo \& Roediger, 2002; Seamon \& cols., 2003). Quanto maior o BAS, ou seja, a força associativa dos alvos para com o distrator crítico, e menor a conectividade dos alvos, mais ativações dele serão esperadas, aumentando o índice de FM's (Deese, 1959; Roediger \& cols., 2001).

Uma distinção importante ocorre no entendimento de processos de codificação e suas interações 
com os de recuperação. A ênfase pode ser dada em ambos. O processamento global do alvo torna-o mais memorável, ajudando na distinção entre as memórias verdadeiras e falsas já que os alvos têm mais características associadas entre si do que os distratores críticos. O processamento relacional, ou seja, a ativação dos itens dele aumentaria a probabilidade da recuperação falsa por conduzir a associações de eventos que na verdade não ocorreram (Roediger \& cols., 2001).

Em experimentos em que há múltiplas apresentações das listas, a AMT diz que o aumento das memórias verdadeiras e o decréscimo das FM's são devidos à prática que permite a ativação diferenciada do que foi apresentado do que não foi, sendo ela responsável tanto pelos altos índices de lembranças (recordação ou reconhecimento) verdadeiras quanto pelos de lembranças falsas (Seamon \& cols., 2003).

O monitoramento da fonte ocorre principalmente no momento do teste, porém pode ocorrer durante a aplicação das listas. Ele funciona no sentido contrário à ativação: diminuindo tanto as lembranças verdadeiras quanto as falsas e, além disso, é derivado de processos de julgamento da teoria do Monitoramento da Fonte (Brainerd \& Reyna, 2005).

Os autores alegam que os problemas das FM's podem ser minimizados através do Monitoramento da Fonte. As propriedades semânticas e léxicas que as palavras provocam, especificamente, discriminar propriedades diagnósticas das não diagnósticas farão com que o recordar e o reconhecer das palavras não apresentadas seja reprimido. Como os alvos são mais prováveis de produzir formas de ativação diagnósticas da apresentação real, a AMT reprimirá a recordação ou o reconhecimento dos distratores mais do que dos alvos, conduzindo a um ganho na acurácia da rede. (Brainerd \& Reyna, 2005; Gallo \& Roediger, 2002).

$\mathrm{O}$ ato de relembrar um evento envolve viajar mentalmente no tempo e reviver a experiência. Durante a recuperação, as memórias recobradas que aparentemente têm detalhes fortes são atribuídas às verdadeiras, embora algumas vezes não o sejam. No DRM, o fato do distrator crítico ter sido fortemente ativado durante a codificação significa que na recuperação, os indivíduos poderão recordá-lo ou reconhecê-lo como tendo sido apresentado (Roediger \& cols., 2001).
No entanto, se o distrator crítico difere dos alvos em alguma dimensão, o índice de FM's pode ser diminuído, exemplificando: se os alvos são palavras pequenas, ortograficamente regulares e depois apresentado, no teste, um distrator crítico bem distinto, torna-se fácil rejeitá-lo nele (Roediger \& cols., 2001).

Por último, mas não menos importante, a teoria da Heurística da Distinção proposta por Daniel Schacter. É uma teoria sobre os processos de decisão que podem influenciar o reconhecimento falso no DRM (Seamon \& cols., 2003); ela é focada numa operação particular de supressão metacognitiva e não faz nenhuma hipótese sobre a representação da memória que gera os alarmes falsos, se embasa em certas pressuposições sobre a natureza da representação das memórias que são criadas durante a apresentação das listas (Brainerd \& Reyna, 2005).

Schacter (2003) afirma que os indivíduos podem diminuir as FM's na recuperação usando a distinção do formato em que os alvos foram avaliados. Para ele, o estudo das imagens resulta em uma memória perceptualmente mais distinta do que somente o das palavras (Gallo, McDermott \& cols., 2001).

A Heurística da Distinção consiste, então, em usar a estratégia de expectativa vívida do fenômeno para guiar o desempenho em testes de memória ao considerar que a recordação e o reconhecimento serão restritos aos itens que provocam a recuperação de memórias vívidas dos itens apresentados (Brainerd \& Reyna, 2005). Em outras palavras, os indivíduos usam um processo metacognitivo, no momento da recuperação, para auxiliá-los na decisão se o item foi ou não apresentado anteriormente (Gallo, McDermott $\&$ cols., 2001).

Schacter (2003) narra experimentos em que as pessoas ouviam palavras e ao mesmo tempo viam as imagens delas ou as mesmas escritas. Eles acreditavam que as pessoas somente afirmariam se lembrar de uma palavra quando pudessem se recordar da imagem, o que diminuiria o índice de FM's visto que, os distratores críticos não trariam à mente nenhuma representação distinta. $\mathrm{E}$ isto realmente aconteceu.

Eles ainda distinguem entre as reduções nas FM's que resultam da heurística da distinção (global) das que vêm do acesso de uma informação específica da lista (local). A primeira é baseada na informação global sobre a distinção dos alvos entre si e a 
segunda, da relativa entre os alvos e distratores. A local pode diminuir as FM's ao predizer que os alvos são mais distintos e discrimináveis que os distratores, ao contrário, a global implica numa mudança global no critério de resposta baseada na memória esperada somente dos alvos. (Gallo, McDermott \& cols., 2001).

\section{Considerações finais}

O estudo das FM's é útil tanto para a expansão do conhecimento da memória em contextos laboratoriais quanto para a Psicologia clínica e diversas áreas do saber, que, de maneira direta ou indireta, lidam com a memória.

Ficou claro com as teorias que sugerir informações e forçar as pessoas a evocá-las pode aumentar a magnitude dos efeitos das FM's (Payne \& cols., 1996). Uma implicação prática deste achado é que quando as pessoas que estão em psicoterapias ou em julgamentos são encorajadas a "contar mais", certamente algumas memórias que aparecerão não serão verdadeiras. Outra implicação é que somente por que o registro das memórias é expresso com confiança, detalhe e emoção, isso não significa necessariamente que o evento ocorreu daquela maneira como foi narrado (Loftus, 2003a).

A pesquisa científica sobre memória tem o potencial de minimizar estes tipos de problemas. Os psicólogos podem ajudar, com seus conhecimentos, não só no cotidiano das pessoas, mas a vários outros profissionais, principalmente aos da área jurídica, que dependem da memória dos indivíduos para bem conduzirem seus trabalhos. Vários pontos teóricos e práticos ainda não foram abarcados pelos estudos já realizados e muitas questões precisam ser melhor desvendadas através de pesquisas. Cabe aos profissionais da área se dedicarem mais aos estudos das Falsas Memórias, tão importante e que pouca atenção tem obtido dos pesquisadores no Brasil.

\section{Referências}

Bartlett, F. C. (1932). Remembering: A study in experimental and social psychology. Cambridge, Mass.: Cambridge University Press.

Brainerd, C. J., \& Reyna, V. F. (1998a). Fuzzy-trace theory and children's false memories. Journal of Experimental Child Psychology, 71, 81-129.
Brainerd, C. J., \& Reyna, V. F. (1998b). When things that were never experienced are easier to "remember" than things that were. Psychological Science, 9, 484-489.

Brainerd, C. J., \& Reyna, V. F. (2002). Fuzzy-trace theory and false memories. Current Directions in Psychological Science, 11, 164-169.

Brainerd, C.J., \& Reyna, V.F. (2005). The science of false memory. Oxford: Oxford University Press.

Brainerd, C. J., Stein, L. M., \& Reyna, V. F. (1998). On the developmental of conscious and unconscious memory. Developmental Psychology, 34, 342-357.

Ceci, S. T., \& Bruck, M. (1998). The ontogeny and durability of true and false memories : A fuzzy trace account. Journal of Experimental Child Psychology, 71, 166-169.

Deese, J. (1959). On the predictions of occurrence of particular verbal intrusions in immediate recall. Journal of Experimental Psychology, 58, 17-22.

Gallo, D. A. (2004). Using recall to reduce false recognition: Diagnostic and disqualifying monitoring. Journal of Experimental Psychology: Learning, Memory and Cognition, 30, 120-128.

Gallo, D. A., \& Roediger, H. L. III. (2002). Variability among list in llicitina memory illusions: Evidence for association and monitoring. Journal of Memory and Language, 47(3), 469-497.

Gallo, D. A., Roberts, M. J. \& Seamon, J. G. (1997) Remembering words not presented in lists: Can we avoid creating false memories? Psychonomic Bulletin \& Review, 4, 271-276.

Gallo, D. A., Roediger, H. L. III., \& McDermott, K. B. (2001). Associative false recognition occurs without strategic criterion shifts. Psychonomic Bulletin \& Review, 8, 579-586.

Gallo, D. A., Mcdertmott, K. B., Percer, J. M., \& Roediger, H. L. III. (2001). Modality effects in false recall and false recognition. Journal of Experimental Psychology: Learning, Memory and Cognition, 27, 339-353. 
Ghetti, S., Qin, J., \& Goodman, G. S. (2002). False memories in children and adults: Age, distinctiveness, and subjective experience. Developmental Psychology, 38, 705-718.

Hicks, J.L., \& Marsh, R.L.(1999). Attempts to reduce the incidence of false recall with source monitoring. Journal of Experimental Psychology: Learning, Memory and Cognition, 25, 1195-1209.

Hicks, J. L., \& Marsh, R. L. (2001). False recognition occurs more frequently during source identification than during old-new recognition. Journal of Experimental Psychology: Learning, Memory and Cognition, 27, 375-383.

Hicks, J. L., \& Starns, J. J. (2005) False memories lack perceptual details: Evidence from implicit word-stem completion and perceptual identification tests. Journal of Memory and Language, 52(3), 3096-321.

Israel, L., \& Schacter, D. L. (1997). Pictorial encoding reduces false recognition of semantic associates. Psychonomic Bulletin \& Review, 4, 577-581.

Johnson, M. K., Hashtroudi, S., \& Lindsay, D. S.(1993). Source monitoring. Psychological Bulletin, 114, 3-28.

Johnson, M. K., \& Mitchell, K. L. (2002). Source monitoring. In J. H. Byrne (Ed.), Learning and Memory (2 $2^{\mathrm{a}}$ ed.) (pp. 628-631). New York: Macmillan References USA.

Kelley, C. M., \& Jacoby, L. L. (2000). Recollection and familiarity. In E. Tulving, \& F. I. M. Craik, The Oxford Handbook of Memory (pp. 215227). Oxford, England: Oxford University Press.

Loftus, E. F. (1995). Memory malleability: Constructivist and fuzzy-trace explanations. Learning and Individual Differences, 7, 133-137.

Loftus, E.F. (1997). Creating false memories. Scientific American, 70-75.

Loftus, E. F. (2003a). Make believe memories. American Psychologist, 277, 867-873.

Loftus, E. F. (2003b). Our changeable memories: Legal and practical implications. Nature Reviews: Neuroscience, 4, 231-234.
Loftus, E. (2005). As falsas lembranças. Revista Viver Mente \& Cérebro, 2, 90-93.

Loftus, E. F., \& Hoffman, H. G. (1989). Misinformation and memory: The creations of new memories. Journal of Experimental Psychology: General, 118, 100-104.

Loftus, E. F., \& Palmer, J. C. (1974). Reconstruction of automobile destruction: An example of the interaction between language and memory. Journal of Verbal Learning and Verbal Behavior, 13, 585-589.

Mazzoni, G. (2005). Crimes, testemunhos e falsas recordações. Revista Viver Mente \& Cérebro, 78-84.

Mazzoni, G., \& Memon, A. (2003). Imagination can create false autobiographical memories. Psychological Science, 14, 186-188.

McDermott, K. B. (1996). The persistence of false memories in list recall. Journal of Memory and Language, 35, 212-230.

McDermott, K. B., \& Roediger, H. L. (1998). Attempting to avoid illusory memories: Robust false recognition of associates persists under conditions of explicit warnings and immediate testing. Journal of Memory and Language, 39, 508-520.

Miller, M. B., \& Gazzaniga, M. S. (1998). Creating false memories for visual scenes. Neuropsychologya, 36, 513-520.

Mitchell, K. L., \& Johnson, M. K. (2000). Source monitoring. In: E. Tulving, \& F. I. M. Craik, The Oxford Handbook of Memory (pp. 179-195). Oxford, England: Oxford University Press.

Mitchell, K. L., Johnson, M. K., \& Mather, M. (2003). Source monitoring and suggestibility to misinformation: adult age-related differences. Applied Cognitive Psychology,17, 107-119.

Payne, D. G., Elie C. J., Blackwell, J. M., \& Neuschatz, J. (1996). Memory illusions: recalling, recognizing and recollecting events that never occurred. Journal of Memory and Language, 35, 261-285.

Reyna, V. F., \& Brainerd, C. J. (1995). Fuzzy-trace theory: Some foundational issues. Learning and Individual Differences, 7, 145-162. 
Reyna, V. F., \& Brainerd, C. J. (1998). Fuzzy-trace theory and false memory: New frontiers. Journal of Experimental Child Psychology, 71, 194-209.

Reyna, V. F., \& Lloyd, F. (1997). F. Theories of false memory in children and adults. Learning and Individual Differences, 9, 95-123.

Robinson, K. J., \& Roediger, H. L. III. (1997). Associative processes in false recall and false recognition. Psychological Science, 8, 231-237.

Roediger, H. L. III., \& McDermott, K. B. (1995). Creating false memories: Remembering words not presented in lists. Journal of Experimental Psychology: Learning, Memory and Cognition, 21, 803-814.

Roediger, H. L. III., \& McDermott, K. B. (2000). Distortions of memory. In E. Tulving, \& F. I. M. Craik, The Oxford Handbook of Memory (pp. 149-162). Oxford, England: Oxford University Press.

Roediger, H. L. III., Watson, J. M., McDermott, K. B., \& Gallo, D. A. (2001). Factors that determine false recall: A multiple regression analysis. Psychonomic Bulletin \& Review, 8, 385-407.

Schacter, D. L. (2003). Os sete pecados da memória: Como a mente esquece e lembra. Rio de Janeiro: Rocco.

Seamon, J. G., Goodkind, M., Dumey, A. D., Dick, E., Aufseeser, M. S., Strickland, S. E., Woulfin, J. R., \& Fung, N. (2003). If I didn't write it, why would I remember it? Effects of encoding, attention and practice on accurate and false memory. Memory and Cognition, 31, 445-257.

Stadler, M. A., Roediger, H. L. III., \& McDermott, K. B. (1999). Norms for word lists that create false memories. Memory and Cognition, 27, 494-500.

Stein, L. M., \& Neufeld, C. B. (2001). Falsas memórias: Por que lembramos de coisas que não aconteceram? Arquivos de Ciências da Saúde UNIPAR, 5, 179-186.

Stein, L. M., \& Pergher, G. K. (2001). Criando falsas memórias em adultos por meio de palavras associadas. Psicologia: Reflexão e Crítica, 14, 353-366.
Sternberg, R. J. (2000). Psicologia cognitiva. Porto Alegre: Artes Médicas Sul.

Watson, J. M., Poole, B.J., Bunting, M.F., \& Conway, A.R.A. (2005). Individual differences in susceptibility to false memory in the DeeseRoediger-McDermott Paradigm. Journal of Experimental Psychology: Learning, Memory and Cognition, 31, 76-85.

Endereço para correspondência:

Cíntia Marques Alves. Rua Dom Silvério, $\mathrm{n}^{\circ}$ 70, Bairro Rosário, CEP: 38440-060, Araguari-MG, Brasil. Email: cintiamalves@yahoo.com.br

Artigo recebido em 04/12/2006.

Aceito para publicação em 13/02/2007.

Artigo derivado da Introdução da Dissertação de Mestrado de Cíntia Marques Alves sob a orientação do Prof. Dr. Ederaldo José Lopes, no Programa de Mestrado em Psicologia, Instituto de Psicologia, Universidade Federal de Uberlândia, MG.

Agradecemos a Lílian Milnitsky Stein e Marília Ferreira Dela Coleta, membros da Banca Examinadora, pelos comentários e sugestões apresentadas. 